\title{
DE LA SOCIEDAD GUARANÍ A LA FAMILIA CATÓLICA. NUEVAS APORTACIONES DESDE UNA PERSPECTIVA DE GÉNERO
}

\author{
Rosa TRIBALdos Soriano \\ Universidad de Alicante
}

Fecha de recepción: enero 2015

Fecha de aceptación: mayo 2015

\section{INTRODUCCIÓN}

La renovación conceptual desarrollada en las últimas décadas por la historiografía en el ámbito de la familia, ha transformado notablemente las cuestiones, modelos y aproximaciones que se han venido proyectando y realizando, en especial, desde la historia social. A través de los últimos trabajos y estudios sobre el tema ${ }^{1}$, puede observarse que el interés por las estructuras y las instituciones se ha ido desplazando hacia las interacciones e interrelaciones dentro de un contexto definido por los recorridos individuales y su integración en las diferentes esferas de la vida social, entre las que destaca la historia de las mujeres ${ }^{2}$.

El Concilio de Trento (1545-1563) fijó un modelo matrimonial y familiar que organizó la sociedad del siglo XVI en las regiones católicas. El matrimonio quedaba como sacramento de la nueva alianza a través de su carácter unitario (que representaba

1. Destacamos especialmente las investigaciones que vienen desarrollándose desde la Universidad de Murcia a través del Seminario Familia y élite de poder, con numerosas publicaciones y congresos. Igualmente hacemos referencia a la obra de carácter general: Bel Bravo, M. Antonia: La familia en la Historia, Ediciones Encuentro S.A., Madrid, 2000.

2. Dávila Mendoza, Dora (coord.): Historia, género y familia en Iberoamérica (ss. XVI-XX), Fundación Konrad Adenauer, Universidad Católica Andrés Bello, Instituto de Investigaciones Históricas, Caracas, 2004; Gonzalbo Aizpuru, Pilar: Género, familia y mentalidades en América Latina, Editorial de la Universidad de Puerto Rico, Puerto Rico, 1997. 
la unión de Cristo y de la Iglesia) y poseía una promisión de gracia; la sacramentalidad era la razón última de su indisolubilidad ${ }^{3}$.

En el mundo colonial, a partir del choque que tuvo lugar con la conquista, se instauraron un conjunto de nuevas formas de convivencia familiar basadas en las disposiciones emanadas de Trento, notablemente diferentes de las que predominaban en el mundo indígena. Quizá por ello, el resultado final de estos contactos fue el establecimiento de ambiguos criterios de moralidad, aplicados de distinto modo al sexo femenino y masculino ${ }^{4}$.

En este trabajo, pretendemos analizar varias cuestiones acerca de la forma de unión y organización social introducida por los misioneros jesuitas entre el grupo guaraní a través del sistema reduccional. Así, ahondaremos en la transición de unos valores ancestrales indígenas a otros occidentales vinculados a la familia en general, y a las mujeres en particular, y los nuevos roles establecidos para las guaraníes dentro de la importancia otorgada al papel de madre y esposa dentro del ámbito católico.

\section{NUEVOS ESPACIOS Y DISCURSO DE DOMESTICIDAD PARA LAS MUJERES GUARANÍES}

La muger ha de cuidar de la limpieza de la casa, y de la familia y del esposo, hacer telas, ocupar la familia, según todo aquello que toca al gobierno de una muger: ha de procurar vivir dentro de casa, como las tortugas, y no ser amiga de callejear, de visitas, amiga de perder tiempo, y de que otras le pierdan por su mal ejemplo 5 .

Estas palabras del jesuita Pedro de Calatayud, a pesar de ser de finales del siglo XVIII, reflejan a la perfección el estilo de vida que impusieron los misioneros a las mujeres en el ámbito reduccional, un proyecto que, aunque no fue original puesto que tenía sus antecedentes en los trabajos misioneros desarrollados bajo otras órdenes ${ }^{6}$, alcanzó su éxito y mayor esplendor entre las misiones de guaraníes, y más concretamente, en los conocidos como Treinta Pueblos Misioneros Guaraníes?

3. Hubert, Jedin: Historia del Concilio de Trento, IV-2: Tercer periodo de sesiones y conclusión. Superación de la crisis gracias a Morone. Conclusión y ratificación, Pamplona, Universidad de Navarra, 1981, pp. 152-153.

4. Gonzalbo Aizpuru, P.: Op. Cit., p. 14.

5. Calatayud, Pedro de SJ: Doctrinas prácticas que solía explicar en sus misiones, Doctrina VI, Parte II, Tratado X, t. III, 1797, pp. 416-417.

6. Anteriormente a la llegada de los jesuitas, los franciscanos con Fray Luis de Bolaños a la cabeza, habían comenzado ya a establecer pueblos entre los guaraníes, siendo fundada la primera reducción llamada San Lorenzo de los Altos o Los Altos (Paraguay), en 1580. La primera misión de los jesuitas (San Ignacio Guazú) no se estableció hasta 1609. NeCKer, Louis: Indios guaranies y chamanes franciscanos. Las primeras reducciones del Paraguay (1580-1800), Biblioteca Paraguaya de Antropología, Vol. 7, Centro de Estudios Antropológicos, Universidad Católica de Asunción, 1990.

7. Para un estudio de las misiones jesuíticas de carácter general ver: MAEDER, Ernesto: Aproximación a las misiones guaraníticas, Ediciones de la Universidad Católica Argentina, Buenos Aires, 1996; Armani, Alberto: Ciudad de Dios y ciudad del Sol, el «estado» jesuita de los guaranies (1609-1768), Fondo de Cultura Económica, México, 1996. Para trabajos desde un punto de vista económico ver: CARBONELL 
Los jesuitas perseguían como fin último conducir a esta población «bárbara» y «salvaje» (así caracterizada tradicionalmente por los cronistas y viajeros al existir, anteriormente a la llegada de esta orden, territorios guaraníes a los que no se habían podido acceder mediante las armas) a «poblaciones grandes, y a vida política y humana, a beneficiar algodón con que se vistan $»^{8}$. Es decir, civilizar significaba cristianizar, por lo que las principales preocupaciones fueron aglutinar a la población que se encontraba dispersa en un mismo lugar para desarrollar en dichos pueblos una comunidad cristiana, eliminar los «vicios» de la población, fundamentalmente las llamadas «borracheras» ${ }^{9}$, la poligamia y las idolatrías, así como cubrir la desnudez de los cuerpos, encarnando estos puntos una reformulación significativa de la forma de vida propiamente indígena y especialmente rupturista con las funciones y cotidianeidad de las mujeres ${ }^{10}$.

DE MASY, Manuel: Estrategias de desarrollo rural en los pueblos guaraníes (1609-1767), Monografías, Economía V centenario, Barcelona, 1992; Melì̀, Bartomeu y Temple, Dominique: El don, la venganza y otras formas de economía guaraní, Centro de Estudios Paraguayos «Antonio Guasch», Asunción, 2004. Estudios que abordan la religiosidad y espiritualidad guaraní: CHAmorro, Graciela: Teología guaraní, Iglesia, pueblos y culturas, Abya-Yala/UPS Publicaciones, Quito-Ecuador, 2004; BranISLAVA, Súsnik: «Los aborígenes del Paraguay» V. Ciclo vital y estructura social, Museo Etnográfico «Andrés Barbero», Asunción, Paraguay, 1983. Sobre la expulsión de los jesuitas de la antigua Provincia del Paraguay ver: WILDE, Guillermo: «Los guaraníes después de la expulsión de los jesuitas: dinámicas políticas y transacciones simbólicas», Revista Complutense de Historia de América, n. ${ }^{\circ}$ 27, 2001, pp. 69-106; PAGE, Carlos A.: Relatos desde el exilio. Memorias de los jesuitas expulsos de la antigua Provincia del Paraguay, CSIC, Fundación Carolina y CONICET, Asunción del Paraguay, 2011.

8. Ruiz de Montoya, Antonio Ss: Conquista espiritual hecha por los religiosos de la Compañia de Jesús, en las Provincias del Paraguay, Paraná, Uruguay y Tape, Madrid, 1639, p. 6.

9. Con el término «borracheras», los misioneros calificaron las fiestas y banquetes comunitarios del grupo guaraní. En estas celebraciones, que eran claves para marcar el ritmo de las relaciones intergrupales, se tomaba la bebida denominada $k a^{\prime} u y^{\prime}$ o chicha (este último término dado por los españoles) que elaboraban las mujeres. Los evangelizadores vieron en estos festejos una serie de «vicios» que debían ser eliminados de raíz: el desenfreno, la lujuria y la violencia debido al componente alcohólico que poseían.

10. Para abordar nuestra cuestión desde una perspectiva no sólo americana, sino también europea, en lo que respecta al estilo de vida de las mujeres en Época Moderna, nos hemos basado en la obra enciclopédica dirigida por la doctora Isabel Morant Historia de las mujeres en España y América Latina, Vol. II, Ed. Cátedra, Madrid, 2005; así como en el libro coordinado por las doctoras Pilar Pérez Cantó y Margarita Ortega López Las edades de las mujeres, Universidad Autónoma de Madrid, 2002. Para un estudio sobre las mujeres guaraníes y sus diferentes representaciones misioneras: BoHN MARTINs, María Cristina: «"Desvergonzadas" ou "Escravas da Virgem": representações femininas nas Cartas Ânuas», Anais Eletrônicos do IV Encontro da Associação Nacional de Pesquisadores de História Latino-Americana e Caribenha, Salvador, 2000, pp. 1-10; Deckmann FleCK, E. Cristina: «De mancebas auxiliares do demônio a devotas congregantes: mulheres e condutas em transformação (reduções jesuítico-guaranis, séc. XVII)», Revista Estudos Feministas (Universidade Federal de Santa Catarina, Brasil), Vol. 14, n. ${ }^{\circ}$ 003, 2006, pp. 617-634. Sobre el espacio guaraní y misionero ver: Levinton, Norberto: «Vivienda y vida privada: la transformación de los conceptos por la acción evangelizadora de la Compañía de Jesús (Provincia Jesuítica de Paraguay, 1604-1767)», Hispania Sacra, n. ${ }^{\circ}$ 99, 1997, pp. 171-188. 
Siendo encargados tanto de lo espiritual como de lo temporal, en las misiones de la recién creada Provincia del Paraguay $(1607)^{11}$, los jesuitas se encontraban amparados para desarrollar su labor misionera por las Ordenanzas de Alfaro $(1611)^{12}$ y reglamentados por las Instrucciones del Padre Provincial Diego de Torres Bollo (1609 y 1610 ${ }^{13}$. Estas últimas fueron las primeras órdenes que recogían cómo debía formarse una reducción, sus características principales, así como la necesidad del aprendizaje de la lengua indígena por parte de los misioneros para persuadir a la población. En esas instrucciones, además, se describía cómo tratar a hombres, mujeres, niñas y niños pequeños, el trabajo diario que debían desempeñar los misioneros, cómo atraer a los caciques de otras poblaciones, instrucciones de cuándo y cómo enseñar la doctrina, etc., sumándose a las anteriores disposiciones otras posteriores ${ }^{14}$.

En este nuevo sistema, las guaraníes fueron confinadas a unos espacios concretos y delimitados donde desarrollar su vida, totalmente diferentes a los tradicionales, viéndose obligadas a aceptar una serie de adaptaciones que no fueron ajenas a conflictos o tensiones. De esta manera, las indígenas quedaron apartadas de sus funciones primigenias y los jesuitas las relegaron a nuevas instituciones creadas para ellas, como el Cotyguazú, o bien promovieron su incorporación en las Congregaciones Marianas para convertirlas en «almas puras, provectas en virtud ${ }^{15}$.

Desde el primer momento, los misioneros no solo limitaron los espacios femeninos, sino que, a su vez, restaron importancia al papel desempeñado por las mujeres en la vida diaria de las misiones. Así, en el nuevo tipo de viviendas, aunque tipológicamente muy similares a las guaraníes, los significados dados por los misioneros al espacio interior supusieron una transformación de la casa comunal que afectó sensiblemente a las mujeres. Igualmente, con la llegada de un concepto nuevo de familia, hasta ahora desconocido por los indígenas, basado en el modelo católico occidental compuesto por padre, madre y descendientes, las mujeres guaraníes se vieron obligadas a dedicarse a su familia bajo los roles de madre y esposa o, por el contrario, tomar la decisión de llevar una vida basada en la castidad.

Vinculado a lo anterior, debemos destacar el tipo de relación que se estableció entre los jesuitas y las mujeres, y que se encontraba reglada mediante las órdenes emanadas por los padres provinciales de las que tenemos varios ejemplos:

11. La conocida como antigua Provincia del Paraguay fue creada por el P. General Claudio Aquaviva en febrero de 1604 e instalada finalmente en 1607, una vez se nombró a Diego de Torres Bollo como primer provincial de la misma.

12. HernáNDEZ, Pablo SJ: Organización social de las doctrinas guaranies de la Compañía de Jesús, Tomo II, Barcelona, 1911, pp. 661-677.

13. Ibidem, Tomo I, pp. 580-589.

14. Reglamento General de Doctrinas enviado por el Provincial P. Tomás Donvidas, y aprobado por el General P. Tirso (1689).

15. Calatayud, Pedro de: Arte y método de hacer missiones, Madrid, 1754, pp. 48-49. 
En la casita de VV.RR. no entren mujeres por ningún respeto ${ }^{16}$; Nunca se hable a mujer alguna sin que esté delante alguno de los Nuestros, o dos indios de toda satisfacción ${ }^{17}$; Cúidese mucho de la clausura en nuestras casas, de suerte que se eche de ver que lo son de la Compañía; y no entre mujer ninguna de la puerta adentro; ni se les dé a besar la mano; ni nadie castigue por su propia mano, ni asista ocularmente a castigo de mujer, ni en el lugar donde se hace el castigo, por la indecencia; dándose a venerar y respetar como dice su regla: Omnis se integritatis et gravitatis exemplum praebeat ${ }^{18}$.

Las mujeres representaban el pecado original y materializaban la tentación a través de sus cuerpos. Como acabamos de ver en el fragmento anterior, la estrategia ignaciana pasó por el distanciamiento con el género femenino, así como la instauración de nuevas reglas de convivencia entre los y las indígenas. Así, el control de la vida sexual constituyó uno de los pilares fundamentales de la labor misionera y una de las facetas de la vida femenina directamente afectada por la evangelización. Dentro del orden reduccional, el cambio de la tradicional relación entre hombres y mujeres comenzaba a operarse a través de una estricta separación entre ambos sexos, que regía incluso para el cumplimiento de los deberes religiosos, como la asistencia a la catequesis. La intervención jesuítica fue crucial, sobre todo, en cuanto a la persecución de ciertas prácticas contrarias a las normas de la fe católica y los sagrados principios de la procreación. La actuación misionera en este aspecto se centró en la erradicación del infanticidio, del aborto, de las uniones libres y de la poligamia, instituyendo en su lugar el modelo de la familia cristiana ${ }^{19}$.

A pesar de las estrictas disposiciones que reglaban la vida de los misioneros en las reducciones y su trato con las indígenas, los jesuitas no solo se vieron obligados a mantener relación y contacto con ellas en multitud de ocasiones como lo demuestran las Cartas Anuas $^{20}$, sino que además los jesuitas debieron aceptar determinadas resignificaciones admitiendo los nuevos sentidos que las mujeres imprimieron estratégicamente a algunos aspectos de la religión católica (como los lamentos fúnebres).

Desde los comienzos del cristianismo las mujeres fueron relegadas a un segundo plano, portadoras del estigma de Eva, consideradas, pues, más proclives al pecado que

16. Primera instrucción del P. Torres, 1609, en Hernández, P.: Op. Cit., p. 584.

17. Reglamento general de Doctrinas enviado por el Provincial P. Tomás Donvidas, y aprobado por el General P. Tirso, Ibídem, p. 594.

18. Ibidem, p. 596.

19. VitAR, Beatriz: «Jesuitas, mujeres y poder: el caso de las misiones de las fronteras del Chaco (siglo XVIII)», en Memoria Americana 12, 2004, p. 49.

20. Las Cartas Anuas eran los informes regulares que los superiores provinciales enviaban al Padre General de la Compañía de Jesús residente en Roma. Se basaban en la información aportada por los superiores de las Residencias, Colegios, Universidades y Misiones, incluyendo largos fragmentos de cartas remitidas por los propios misioneros y presentando la ventaja de ofrecer un cuadro general de las situaciones distintas en que se encuentran los jesuitas según los distintos lugares y momentos de sus relaciones con las comunidades indígenas. Las Cartas Anuas conforman un vasto cuerpo que cubre un amplio espacio temporal ininterrumpido, abarcando desde los inicios de la Provincia Jesuítica del Río de la Plata (1609), hasta 1762, año próximo a la expulsión definitiva de los jesuitas de los dominios de la corona hispánica 
los hombres. En consecuencia, para los misioneros no poseían las virtudes de la sensatez, el juicio y el discernimiento, por lo que debían trabajar directamente en disponer un modelo de conducta más adecuado para ellas (el aplicado para las mujeres occidentales) y que de esta manera evitaran el mal y el pecado.

Ya san Pablo estableció la conducta femenina ideal, aquella en la que la mujer se sometía al hombre: «la cabeza de todo varón es Cristo; la cabeza de la mujer es el varón; y la cabeza de Cristo es Dios. Toda mujer que ora o habla en nombre de Dios con la cabeza descubierta, deshonra su cabeza. Por eso, la mujer debe llevar sobre su cabeza la señal de sujeción ${ }^{21}$. La idea de la vigilancia y el control de las prácticas femeninas, así como las referencias sobre el cuidado que había de prestarse a las miradas de las mujeres, puede observarse en el Tesoro de la Lengua guaraní del misionero Antonio Ruiz de Montoya con las expresiones: «mala mujer», «mujer que anda con todos», «andariega», «mujer de mirada deshonesta» o «mujer liviana» ${ }^{22}$.

La domesticación femenina a partir de las prescripciones dadas, disponía que las mujeres debían mantenerse en el silencio y la obediencia más absoluta respecto de los hombres. Este precepto, hizo que las guaraníes quedaran confinadas al ámbito de la vivienda y apartadas por completo no sólo de sus antiguas funciones en el ámbito espiritual, sino también que se mantuvieran al margen de la esfera pública de la vida misionera. Para aleccionar y enseñar a las guaraníes el modelo que debían seguir, los misioneros recurrieron especialmente a la evangelización a través de las imágenes y, en concreto, la de la Virgen María como ejemplo de vida. Sus características principales, pudor, virtud, virginidad, símbolo de maternidad casta, sirvieron como pauta a las nuevas cristianas para alcanzar ese comportamiento ideal al que todas debían aspirar, dando lugar así a una potenciación del culto mariano en las reducciones.

\section{LA VIVIENDA COMO VEHÍCULO PARA LAS PRIMERAS TRANSFORMACIONES DE LA SOCIEDAD GUARANÍ}

Resulta muy interesante analizar el modo en que los diferentes aspectos de la realidad indígena debían ser reducidos, es decir «civilizados», y cómo fueron conceptuados y tratados «políticamente» mediante actitudes y acciones que pretendían un cambio cultural. La poligamia y las viviendas comunales fueron las dos esferas que centraron el interés de los misioneros desde el primer momento. Las transformaciones llevadas a cabo en este sentido condujeron a la aparición de la casa unicelular, la familia católica, el matrimonio monogámico y nuevos conceptos que englobaban estereotipos en relación a las mujeres como los de esposa o la idea de virginidad.

21. I Corintios, 11, 3-4 y 10.

22. Ruiz de Montoya, Antonio SJ: Tesoro de la lengua guaraní, Madrid, 1639, p. 107. En el Tesoro, existen más de sesenta expresiones dedicadas a la mujer y treinta y dos de ellas la presentan como protagonista de los «pecados carnales», Chamorro, Graciela: Teología Guaraní, Colección Iglesias, Pueblos y Culturas n. ${ }^{\circ}$ 61, Abya Yala, Quito-Ecuador, 2004, p. 207. 
Una de esas primeras modificaciones efectuadas en el denominado «espacio guaraní-misionero», es decir, el espacio geográfico, económico, político y sociocultural conformado por los treinta pueblos jesuítico-guaraníes y sus comarcas ${ }^{23}$, fue el hecho de establecer a las parcialidades ${ }^{24}$ guaraníes en asentamientos concretos, lo que supuso que la población pasara a ser sedentaria, un rasgo que no era habitual entre estos grupos seminómadas que fundamentaban su vida en la caza, la recolección y la explotación de la tierra que, cuando se agotaba, los obligaba a trasladarse a otro lugar.

La configuración de la sociedad guaraní tradicional se basaba en las grandes casas comunales, llamadas en portugués maloca y en guaraní tapy-guazú. Un pueblo podía albergar varios cientos de personas, ubicadas en varias de estas viviendas colectivas, de diversas formas y tamaños. Cada grupo familiar ocupaba un determinado espacio de la vivienda y entre dos grandes postes se colocaban hamacas de algodón o fibra de palmera, así como algunos muebles y utensilios. En estas casas podían llegar a convivir entre diez y sesenta familias emparentadas entre sí, constituyendo un linaje patrilineal denominado tey' $i$, formando el grupo macrofamiliar unido por parentesco y habitando en una casa común que era a su vez la expresión de la unidad socioeconómica.

El lugar principal por excelencia de la vivienda guaraní era el fogón o fuego doméstico, el tataipi ${ }^{25}$, donde se encontraban las mujeres no sólo cocinando y realizando las labores domésticas: el hecho de permanecer junto al fuego poseía un sentido espiritual al estar considerado el lugar de asentamiento de la palabra, con todo lo que la «palabra» significaba para esta cultura ${ }^{26}$, pudiéndose constatar escenas frecuentes de mujeres como dueñas de la luz o vinculadas a las llamas y el fuego en los relatos de la Conquista Espiritual de Ruiz de Montoya ${ }^{27}$. Para entender un poco más la importancia del lenguaje en esta cultura, cabría decir - de forma muy esquemática y siguiendo al $\mathrm{P}$. Melià- que la palabra tenía un gran valor entre el pueblo guaraní, de ahí que sus líderes políticos y espirituales (tanto hombres como mujeres) debían poseer como característica principal el ser grandes oradores. Por este mismo motivo, cuando la Compañía de Jesús llegó a territorio guaraní, fueron bien recibidos e incluso escuchados ante la elocuencia de los padres. Dada la gran importancia que otorgaban y otorgan aún en la

23. WILDE, Guillermo: «Los guaraníes después de la expulsión de los jesuitas: dinámicas políticas y transacciones simbólicas», Revista Complutense de Historia de América, Vol. 27, 2001, p. 74.

24. Utilizaremos el concepto de «parcialidad» para referirnos a los distintos grupos que, aunque provienen del mismo tronco familiar guaraní, poseen distinciones y particularidades generadas a nivel microgrupal sin que ello suponga descartar el sustrato étnico común que comparte un grupo humano procedente de la misma rama.

25. Ruiz de Montoya, A.: Tesoro..., p. 357.

26. Melià, Bartomeu S.J.: «La obra lingüística de Antonio Ruiz de Montoya, s.j.», Real Academia de la Lengua, Madrid, 2012; La lengua guarani del Paraguay: historia, sociedad y literatura, Mapfre, Madrid, 1992; «La entrada del castellano en el Guaraní del Paraguay», en El guaraní conquistado y reducido. Ensayos de Etnohistoria, Biblioteca Paraguaya de Antropología, Vol. 5, Tercera edición, Centro de Estudios Antropológicos, Universidad Católica, Asunción, 1993, pp. 237-248; «Conquistar la lengua Guaraní», Ibídem, pp. 249-259.

27. Ruiz de Montoya, A.: Conquista espiritual..., p. 40. 
actualidad los grupos guaraníes a la palabra, tenían un gran amor hacia su idioma y tuvo que pasar mucho tiempo hasta que pudo introducirse el castellano, en este caso entre los indígenas reducidos. Esta actitud fue captada rápidamente por los misioneros, quienes mantuvieron en las reducciones el guaraní como única lengua hablada y escrita, adoptando un carácter cuasi-oficial, a pesar de haber perdido dicha lengua la autonomía que le daba el modo de ser tradicional, con sus discursos políticos, religiosos y hasta coloquiales, sustentados ahora en otra cultura al ser reducida, igualmente que sus pobladores, a formas coloniales.

Alrededor del tataipí y de las mujeres se reunía la comunidad; en torno al fuego se desarrollaba la comunicación y el intercambio entre las generaciones en forma de relatos y voces, significando esta práctica, por un lado, una invitación dirigida a la gran familia para reunirse alrededor del fuego y escuchar la palabra y, por otro, una plegaria destinada a que la palabra guaraní no perdiera su virtud salvadora entre las siguientes generaciones ${ }^{28}$. Podemos llegar a intuir que madres y abuelas guaraníes manejaban y usaban el vocabulario para generar conciencia de grupo e incluso, generar cohesión social. Este constituye un fenómeno que puede ser analizado no sólo durante la época prehispánica y la conquista (al ser ellas las que transmitían el idioma a su descendencia, incluso mestiza), sino que debe precisarse que, tras la expulsión de la Compañía, las mujeres fueron las que mantuvieron vivo el guaraní hasta la actualidad. Por estos motivos los misioneros, una vez que llegaron y observaron la importancia de las voces femeninas, conscientes de su papel como protectoras del lenguaje y el valor que adquiría el fuego, decidieron de forma tajante enmudecer su palabra (salvo en los casos donde ejercían de visionarias), como consecuencia de la ideología católica patriarcal y europeísta del momento, donde no se aceptaba que las mujeres hablaran sobre temas que afectaban a la sociedad circundante por su condición de «sexo débil»; de la misma manera, el lugar de asentamiento de la palabra pasó a ser el púlpito.

Tradicionalmente, las viviendas eran erigidas de forma conjunta, siendo motivo de fiesta desde su construcción hasta su inauguración. Además de la significación social y ceremonial que poseían, uno de los rasgos culturales más característicos del grupo guaraní fue la convivencia de varias familias bajo un mismo techo, contribuyendo a aumentar y garantizar las relaciones personales, grupales e intergrupales, así como a generar una mayor cohesión, consiguiéndose en definitiva una mejor defensa física y dependencia mutua ${ }^{29}$. Esta convivencia comunitaria no fue vista positivamente desde la óptica jesuítica y fue modificada por completo, cambiando la forma de comunicarse y relacionarse que poseía anteriormente el grupo. Las transformaciones más importantes respecto a las viviendas de las misiones venían dadas por lo que el misionero Roque

28. Lustig, Wolf: «Literatura paraguaya en guaraní», América sin nombre, n. ${ }^{\circ}$ 4, 2004, p. 59.

29. Palacios, Silvio y Zoffoli, Ena: Gloria y tragedia en las misiones guaranies. Historia de las reducciones jesuiticas durante los siglos XVII y XVIII en el Rio de la Plata, Mensajero, Bilbao, 1991, pp. 96-97-98. 
González de Santa Cruz definía como «inconvenientes» y que debían ser erradicados para evitar la ocasión de «borracheras y otros crímenes...»»

Entre las dificultades y obstáculos que existían para la instalación de la familia católica destacaba especialmente la lujuria como una característica intrínseca de la vivienda colectiva. Así lo explicaba el P. Pablo Hernández:

Además de tener el excitante de la borrachera, acostumbraban andar totalmente desnudos, y vivían en casas grandes, chozas o aduares que, sin división alguna interior, encerraban todos los sujetos grandes y pequeños, de uno y otro sexo, no sólo de una misma familia, sino de varias afines entre sí y aun extrañas, [contando además entre sus usos] el de la poligamia con otros bien contrarios a la honestidad ${ }^{31}$.

De esta manera, el proceso de transformación de las viviendas guaraníes con motivo de la llegada del catolicismo pasó por mantener la estructura alargada y rectangular pero modificándose internamente. Se incorporaron, por tanto, nuevos significados: en las misiones, la vivienda guaraní contó con una separación en compartimentos y se estableció la familia celular tal cual era concebida por la Iglesia, ayudando de esta manera a la desaparición de la poligamia, problema que preocupaba profundamente a los misioneros, consolidándose el matrimonio monogámico.

\section{MONOGAMIA Y MATRIMONIO: NUEVOS CONCEPTOS QUE AFECTARON A LAS MUJERES EN EL ÁMBITO DE LA FAMILIA}

La vida en las reducciones estaba organizada y controlada hasta el mínimo detalle por los padres jesuitas. Los hombres y las mujeres tenían ámbitos de vida y de trabajo claramente separados. Fuera del estrecho núcleo familiar, apenas había posibilidades de relacionarse ${ }^{32}$.

Del análisis de la documentación histórica existente, sabemos que la familia fue uno de los ámbitos donde se entabló una dura batalla entre el precedente sistema de relaciones sociales y el nuevo impuesto por los padres ignacianos. De hecho, el propio término «familia» que caracterizaba el universo católico para los siglos modernos, no entraba dentro del esquema social de las culturas indígenas americanas, para quienes la familia era fundamentalmente la comunidad.

Desde el momento de la conquista, en un espacio tan variado y complejo, se intentó aplicar el modelo de familia cristiana bajo las prescripciones de la Iglesia católica, tema de estudio que desde hace varias décadas constituye un desafío notable, especial-

30. González de Santa Cruz, Roque: Carta del 8 de abril de 1614, Residencia del Paraná, en Moreno, Fernando M., Carbonell de Masy, Rafael y Rodriguez Miranda, Tomás: «Para que los indios sean libres»: Escritos de los mártires de las Reducciones guaranies, Centro de Espiritualidad Santos Mártires, Limpio, Asunción, Paraguay, 1994, p. 49.

31. Hernandez, P.: Op. Cit., Tomo 1, p. 75.

32. Potthast-Jutkeit, Bárbara: «Paraíso de Mahoma»o «País de las mujeres»?, Instituto Cultural Paraguayo-Alemán, Asunción, 1996, p. 51. 
mente cuando se reflexiona sobre el éxito o fracaso de dicha imposición ${ }^{33}$. El sistema de organización y reproducción social que regía en occidente bajo la mirada católica, dentro del cual se encontraba tanto el modelo de matrimonio como el concepto de familia legítima, se trasladó a América. Como ya hemos comentado, estos modelos procedían de los postulados tridentinos, que rigieron en los territorios de Indias a partir de 1564, ratificando la doctrina clásica de la Iglesia en cuanto al matrimonio como institución religiosa, de carácter sacramental, monogámico e indisoluble ${ }^{34}$.

Con la intención de modificar el status de las mujeres indígenas, el sistema misionero estableció una jerarquización de género a través de actividades específicas, lugares y horarios de circulación. Además, el cuerpo femenino también fue motivo de atención por parte de los jesuitas y su protección se intensificó, siendo necesario encerrarlo y silenciarlo ${ }^{35}$. De esta manera, la base sobre la que se llevó a cabo la reestructuración de la sociedad indígena guaraní en las reducciones fue la imposición de la familia monogámica y patriarcal. Es cierto que la cultura guaraní igualmente poseía unas características que podrían incluirse bajo el término «patriarcado»; sin embargo, este concepto ha venido aplicándose a las culturas indígenas bajo el término «patriarcado ancestral», donde sí que existía, por ejemplo, una filiación por descendencia patrilineal, pero en la práctica mucho menos fuerte que en el mundo occidental, ya que se asentaba en una equidad entre hombres y mujeres que impedía la dominación exclusivamente masculina.

Con la atomización de la sociedad aborigen en pequeñas familias bajo el nuevo planteamiento, los misioneros consiguieron sobre todo el derrumbe de la familia exten$\mathrm{sa}^{36}$. Igualmente, con la instauración de estos nuevos conceptos, se colonizó el «alma» indígena pero, a su vez, también se apropiaron de su percepción, de sus cuerpos y de su sexualidad utilizando el miedo como medida de control y de represión del comportamiento sexual, especialmente el femenino.

En la sociedad guaraní premisionera, las uniones eran por lo general monógamas, siendo la poligamia, además de exclusivamente masculina, practicada sobre todo por los caciques o jefes de la comunidad, por lo que era entendida más bien como un privilegio que como una costumbre habitual. Si analizamos las descripciones realizadas por los misioneros, observamos que veían en la poligamia el camino de la lujuria, del libertinaje sexual y el desenfreno, sin poder llegar a asumir que precisamente esta práctica entre el grupo guaraní no solamente formaba parte de sus más ancestrales tradiciones,

33. Rypodas Ardanaz, Daisy: El matrimonio en Indias. Realidad social y regulación jurídica, FECIC, Buenos Aires, 1977; Lavrin, Asunción (coord.): Sexualidad y matrimonio en la América Hispánica. Siglos XVI-XVIII, México, Consejo Nacional para la Cultura y las Artes-Grijalbo, 1991.

34. El Sacramento del Matrimonio aparece en la sesión XXIV del Concilio de Trento, en tiempos del Sumo Pontífice Pío IV, celebrada el 11 de noviembre de 1563.

35. Cavilha Mendes, Isackson L.: As mulheres indígenas nos relatos jesuíticos da Província do Paraguai (1609-1768), Dissertação (Mestrado)- Universidad Federal do Rio Grande do Sul, CIP-Catalogação na Publicação, Porto Alegre, 2013, p. 56.

36. Chamorro, G.: Op. Cit., pp. 102-103. 
sino que además tenía su fundamento en la organización política y económica de los pueblos en relación a las actividades y trabajos que desarrollaban las mujeres y en la que se apoyaba todo su sistema ${ }^{37}$. Además, debe tenerse en cuenta que en la sociedad guaraní las mujeres poseían una importancia económica y social muy considerable. Por un lado, desde un punto de vista económico, tenían grandes responsabilidades en el trabajo, como se ha apuntado principalmente en las actividades agrícolas; por otro, su importancia social radicaba en que a través de las figuras femeninas se desarrollaba el denominado «cuñadaje», una institución a través de la cual los hermanos de la esposa pasaban a formar parte de la familia extensa del marido, como parientes y productores $^{38}$.

Durante los primeros años del periodo misional, las tensiones entre la organización tradicional guaraní y la instalación de la familia cristiana fueron evidentes porque la percepción y la idea sobre las relaciones matrimoniales eran diametralmente opuestas. De hecho, el misionero Montoya cuenta que «aunque en ella [la doctrina] y los sermones que haziamos todos los Domingos tratábamos con toda claridad de los misterios de nuestra santa Fe, y de los preceptos divinos, en el sexto [mandamiento] guardamos silencio en público, por no marchitar aquellas tiernas plantas, y poner odio al Evangelio. Duró este silencio dos años» ${ }^{39}$.

Para instruir a los neófitos, se recurrió a la mejor arma de la que disponía la Compañía de Jesús: la educación. Una formación especialmente destinada a los más jóvenes, que no poseían la tradición indígena tan arraigada como podían tenerla los mayores, intentando formar en el periodo más breve de tiempo posible el mayor número de unidades familiares cristianas y conseguir la instalación del matrimonio cristiano en el plazo de unas décadas. Los misioneros persuadieron a los cabezas de familia para que al hijo, cumplidos ya los 17 años, le buscaran una esposa digna y, a su vez, a la hija cumplidos los 15, le indicasen un esposo. Pareció que esta era la mejor edad, una espera más prolongada podría ser motivo de «lujuria» para los jóvenes, y al contrario, no esperar la madurez, traería la perturbación del orden doméstico y la honesta convivencia por la debilidad de la mente y la inestabilidad del ánimo de los jóvenes esposos. Según cuenta el P. Antonio Sepp, eran las mujeres quienes pedían el matrimonio al hombre:

37. Las mujeres eran quienes tenían la responsabilidad de multitud de trabajos, entre los que destaca el agrícola, dedicándose a la recolección de alimentos silvestres, la siembra y la cosecha de los productos de los cultivos familiares, así como encargarse del transporte de los frutos de la chacra a la aldea. También eran las responsables de la crianza y cuidado de sus hijos e hijas, construían las casas con el resto del grupo de forma colectiva, mantenían la limpieza de la vivienda, cuidaban del fuego familiar, preparaban los alimentos, recogían el agua y elaboraban la bebida por excelencia del mundo guaraní, el ka 'u'ý o chicha. Igualmente las mujeres se dedicaban a la fabricación de utensilios cerámicos, a la cestería y a la elaboración de tejidos. En definitiva, se evidencia la existencia de un papel protagonista y fundamental de las mujeres en lo que respecta al funcionamiento de la comunidad y su economía [base económica] tanto en los momentos de paz como de guerra.

38. Chamorro, G.: Op. Cit., pp. 101-102.

39. Ruiz de Montoya, A.: Conquista Espiritual..., p. 15. 
Cuando los indios quieren contraer matrimonio, de ninguna manera el indio solicita a la india, sino al revés, la mujer debe solicitar al hombre para casarse. De modo que una india viene hacia mí y me dice: «Pay, quiero tomar a éste o aquél en matrimonio, si estás conforme». Entonces hago venir al indio y le digo: «Fulana de tal te ha solicitado a ti, hijo mío, como marido, ¿estás de acuerdo? Si dice que sí (y casi siempre dicen que sí), no se necesita nada más, todo está arreglado, hecha la acción y la boda inminente ${ }^{40}$.

Ante la práctica de la poligamia, los jesuitas llegaron a pensar que entre los indígenas no existía el amor ni tampoco el concepto de unión entre los miembros de una familia al ver que ante la llegada de un visitante al grupo, el cacique, ofrecía algunas de sus hijas para así formalizar la relación con la persona recién llegada, al igual que hicieron con los primeros europeos con los que mantuvieron contacto y de hecho, también se las ofrecieron a los jesuitas.

De esta manera, comenzaron los misioneros a investigar cómo se habían realizado las uniones entre los indígenas, creyendo algunos que simplemente eran meros concubinatos, pudiendo los hombres repudiar a las mujeres en cualquier momento, y otros, pensando que los matrimonios sí eran válidos, pues entre los guaraníes se diferenciaba a la primera mujer con la que se había unido del resto de mujeres posteriores. Pidiendo opinión al Papa Urbano VIII, se optó por respetar el parecer más favorable para los indígenas en relación al matrimonio una vez hubieran sido bautizados.

Así, los misioneros tuvieron mucho cuidado y actuaron con gran precaución a la hora de establecer el matrimonio cristiano, dejando que el hombre decidiera con cuál de sus mujeres quería seguir casado bajo la tradición católica, quedando abandonadas el resto de esposas y recluidas en una construcción creada por los misioneros denominada Cotyguazú, donde se ubicaban a aquellas mujeres viudas, huérfanas, solteras y abandonadas, ya que la ética cristiana que los jesuitas practicaban condenaba tanto la poligamia como el repudio a la mujer. Sin embargo, la consecuencia real de la aparición de la monogamia fue el abandono constante de mujeres por parte de algunos hombres que, al no querer renunciar a la poligamia, desatendieron a sus mujeres huyendo a vivir fuera de la misión y teniendo los misioneros que erigir estas «Casas de Recogidas» que, por otra parte, también sirvieron para controlar la vida sexual de las indígenas, en concreto, en lo que respecta a las prácticas abortivas y el infanticidio que realizaban las mujeres guaraníes sin ningún tipo de intercesión masculina, siendo este espacio donde las mujeres ejercían su poder, y que los misioneros quisieron controlar y finalmente eliminar a través del Cotyguazú.

Según la explicación del misionero José Cardiel, la construcción habría formado parte de una política de control de las costumbres, de las femeninas en concreto, llegando a traducir el término Cotyguazú como «Casa de Recogidas» o «Casa de la Madre de Dios». Dicho edificio, alejado de la vivienda de los misioneros, estaba formado por varias salas que daban salida a un patio interno. Llamamos la atención sobre la única

40. SEPP, Antonio SJ: Relación del viaje a las misiones jesuíticas. Ed. Crítica de las obras del padre Antonio Sepp S. J., misionero en la Argentina desde 1691 hasta 1733, a cargo de Werner Hoffmann, Tomo I, EudebA, Buenos Aires, 1971, pp. 200-201. 
puerta por la que se accedía al edificio, cerrada con dos llaves diferentes, ubicándose dos porteros, uno por fuera y otro por dentro: el guardián exterior era un hombre y en el interior estaba una mujer de edad madura, debiendo de poseer ambos una actitud intachable para el control efectivo de la casa ${ }^{41}$. Bajo nuestro punto de vista y a pesar de algunas controversias existentes en la historiografía sobre esta construcción, creemos en las palabras del P. Cardiel al referirse a su finalidad: efectivamente, su edificación estuvo íntimamente relacionada con la estrategia de control de la sexualidad femenina por parte de los jesuitas. Incluso, con el tiempo, llegó a convertirse también en cárcel para mujeres. Las que residían en el Cotyguazú, no solían participar de la vida diaria de las misiones, salvo en los momentos de rezo comunitario en la iglesia, llevando más bien una vida parecida a la conventual y cuyas únicas funciones eran tejer y cumplir la condena impuesta en caso de haber sido encarceladas por delitos. Si tenemos en cuenta que hubo una Casa de Recogidas en cada misión, debemos resaltar la importancia que tuvo este edificio advirtiendo el considerable número de mujeres que debieron ser enclaustradas en el Cotyguazú y que únicamente veían a los misioneros a la hora de las confesiones.

La también llamada «Casa de Viudas» fue una institución sobre la cual apenas existen referencias ${ }^{42}$, por lo que destacamos su trascendencia en las misiones y echamos en falta estudios más profundos sobre su significado ${ }^{43}$. La fecha de su creación, 1714, nos parece clave para reflexionar, no sólo acerca de esta «Casa de Recogidas», sino también sobre la fundación y consolidación de la monogamia en ese periodo. En un momento en el que prácticamente las treinta misiones se encontraban afianzadas, con la imposición del matrimonio cristiano y la desaparición de la poligamia, se hizo necesario reubicar a todas aquellas mujeres que se encontraban solas o habían sido abandonadas (segundas y terceras esposas). Así, en una situación de casi plena autonomía en esa vivienda colectiva femenina, nos preguntamos también si se pudieron establecer entre ellas redes de solidaridad e incluso, si pudieron plantear estrategias para resignificar y reintroducir algunas de las tradiciones antiguas dentro de ese imaginario puesto que, además, en el Cotyguazú también residían indígenas de otras parcialidades todavía «infieles» que habían sido recogidas por los misioneros en sus expediciones.

Respecto a la condición de las mujeres dentro del grupo guaraní, los jesuitas observaron su protagonismo dentro de la comunidad, sorprendiéndose de los trabajos

41. Bruxel, Arnaldo: Los treinta pueblos guaranies. Panorama histórico institucional, Ed. Montoya, Asunción, 1984, p. 56.

42. ImOLESI, María Elena: «El sistema misional en jaque: la reclusión femenina en las reducciones jesuíticas de guaraníes», Anos 90 (Revista do Programa de Pós-Graduação em História da Universidade Federal do Sul), Vol. 18, n. ${ }^{\circ}$ 34, Porto Alegre, 2011, pp. 139-158.

43. En las reducciones del Chaco, la dirigencia femenina fue reutilizada por los misioneros para controlar ciertos ámbitos de la vida productiva como el hilado, el tejido y el teñido que, en el caso de los mocovís, se puso bajo la supervisión de una «vieja india, cacica enviudada», en VITAR, Beatriz: «Jesuitas, mujeres y poder: el caso de las misiones de las fronteras del Chaco (siglo XVIII)», Memoria Americana 12, 2004, p. 60. Seguramente también dentro de la «Casa de Recogidas», serían las viudas las personas que organizaban las labores de hilado y tejido que debían realizar las enclaustradas. 
que debían realizar y su condición dentro de la estructura de la poligamia. Los misioneros creyeron que hacían un gran favor a las indígenas instaurando el matrimonio cristiano indisoluble, eliminando la embriaguez y asignándoles un papel subordinado más propio del denominado «sexo débil». Sin embargo, a pesar de que pueda deducirse que el cristianismo fue para las guaraníes una religión «progresista», que aceptaron sin crítica alguna y que asumieron su papel en la evangelización para convencer a los hombres de la necesidad de la conversión, las mujeres no opinaban así, sino todo lo contrario. Con la aparición de un nuevo tipo organización familiar y una nueva forma de «ser mujer», se desarrolló una sociedad basada en la diferencia sexual, que hizo que las mujeres perdieran la oportunidad de expresar su espiritualidad, así como de participar protagónicamente, como hasta ese momento lo habían hecho, en la religión, la economía y la sociedad como parte activa del grupo al que pertenecían.

\section{REFLEXIONES FINALES}

Como consecuencia de los cambios introducidos con la llegada del sistema misional, la documentación refleja una clara resistencia por parte de la población indígena al reivindicar sus antiguas costumbres e intentar concienciar al grupo para llevar a cabo una «desconversión» y abandonar la vida en la misión. De hecho, nos preguntamos sobre la posible existencia, en el ámbito doméstico, de espacios de conflictividad entre las familias, donde tal vez las mujeres fueran las que convencían a su grupo familiar sobre la necesidad de abandonar la misión y no adaptarse al estilo de vida impuesto por la Compañía o incluso, de ser las generadoras de conflictos entre caciques y misioneros. Aunque las fuentes no describen explícitamente a las mujeres como reacias al sistema reduccional y teniendo en cuenta que fue el ámbito interno de cada vivienda el espacio en el que tuvo lugar la lucha por mantener las antiguas costumbres, sabemos que las mujeres también defendieron el denominado Ñande Reko, el modo en como los indígenas vivían su espacio circundante y la estructura esencial de su cultura ${ }^{44}$. Ciertamente la «reducción»-y lo que ésta conllevaba (organización familiar diferente, nuevo sistema de trabajo, cambios en la relación de los sexos, etc.)-, se oponía profundamente al tekoha guaraní, el lugar donde hasta ese momento se había generado

44. A lo largo de la documentación se hace referencia continua, tanto por parte de los guaraníes como por parte de los misioneros, al «modo de vivir» y al «ser propio» guaraní. La palabra que se adivina detrás de estas expresiones en castellano es teko; según el P. Montoya en su Tesoro de la lengua guaraní (p. 363) el término teko hace referencia al «modo de ser, modo de estar, sistema, ley, cultura, norma, comportamiento, hábito, condición, costumbre». Al traducir al guaraní la obra Conquista Espiritual, allí donde el castellano decía «costumbres» y «modo de vivir», se restableció la expresión Ñande Reko, sabiendo que ella reproduce adecuadamente la expresión original del discurso indígena, en MeLiÀ, B.: «El "modo de ser" guaraní en la primera documentación jesuítica (1594-1639)», en El guaraní conquistado y reducido. Ensayos de Etnohistoria, Biblioteca Paraguaya de Antropología, Vol. 5, Tercera edición, Centro de Estudios Antropológicos, Universidad Católica, Asunción del Paraguay, 1993, pp. 100-103. Para más información ver: Nande Reko. La comprensión guaraní de la Vida Buena, Bolivia, 2008, disponible en: http://www.unicefninezindigena.org.ar/pdf/Legislacion/comprension_guarani.pdf. 
y desarrollado su cultura. De hecho, la documentación analizada evidencia una clara confrontación entre dos modos de ser, entre dos culturas: el ñande reko tradicional y el teko pyahu, que remite al sistema nuevo, y que evidentemente no podía satisfacer a los guaraníes ${ }^{45}$.

Aunque en las fuentes, especialmente las de origen jesuítico, las mujeres aparecen representadas como seres sumisos, también observamos, habida cuenta del estilo de vida que llevaban las indígenas anteriormente al contacto, la presencia de mujeres valientes, conscientes de su pérdida de poder, enérgicas, activas, que no se doblegaron y no se convirtieron al cristianismo, ni abandonaron su «antiguo modo de ser», existiendo por tanto una rica pluralidad y diversidad de actitudes frente a la imposición del sistema reduccional.

En las misiones, la imposición de los nuevos conceptos de «madre» y «esposa» modificaron las relaciones entre ambos sexos y la concepción misma de ser mujer. De ser partícipes en la vida pública y económica de su comunidad, pasaron a quedar recluidas en las viviendas, dedicándose al ámbito doméstico (crianza y cuidado de hijos e hijas), desprovistas de toda posibilidad de ser agentes activos en el espacio social misionero, debiendo seguir el modelo de esposa cristiana y teniendo como referente la imagen y atributos de la Virgen María. Las ocupaciones femeninas se circunscribían al hogar y el cuidado de la familia: el hilado y la costura eran las actividades idóneas que inmovilizaban el cuerpo, las aislaban, y las mantenían en el oscurantismo. Además, la llegada de una nueva religión basada en un dios único y masculino, hizo que la mujer quedara oculta y relegada, mientras que el dominio del padre de familia sobre la tierra y la mujer, por supuesto sumisa a su voluntad, quedaba totalmente establecido y justificado ideológica y socialmente.

Con nuestro estudio intentamos ir más allá de los estereotipos mantenidos acerca de las mujeres, en este caso de la parcialidad guaraní, porque -aunque muchas aceptaron (aunque con matices) un discurso que las situó en un segundo plano- no debemos olvidar que, al mismo tiempo, otros sectores de la población guaraní, como las ancianas, fueron reticentes a la evangelizació ${ }^{46}$. En este sentido, es posible analizar revueltas y críticas tanto en los primeros años de las misiones oponiéndose a la llegada de ese nuevo sistema de organización familiar, como a principios del siglo XVIII, donde todavía quedaban reductos de hostilidad hacia los misioneros, ya que como sabemos los cambios culturales y de mentalidad suelen transitar más lentamente en el repertorio simbólico y conceptual de una comunidad.

45. Melià, B.: «El “modo de ser” guaraní en la primera documentación jesuítica (1594-1639)», en Melià, B.: El guaraní conquista y reducido..., p. 105.

46. Para más información sobre las ancianas, aunque del grupo chaqueño del noreste de Argentina, pero igualmente válido en muchos aspectos para las guaraníes antes y durante las misiones, ver: VITAR, Beatriz: «El poder jesuítico bajo amenaza: Importancia de las viejas en las misiones del Chaco (siglo XVIII), en Estudios sobre América: siglos XVI-XX, Asociación Española de Americanistas, Sevilla, 2005. 